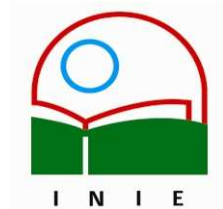

Actualidades Investigativas en Educación

Revista Electrónica publicada por el

Instituto de Investigación en Educación

Universidad de Costa Rica

ISSN 1409-4703

http://revista.inie.ucr.ac.cr

COSTA RICA

\title{
BASES TEÓRICAS Y CONSIDERACIONES PRÁCTICAS EN LA ELABORACIÓN DE MATERIAL MULTIMEDIA PARA UN CURSO DE CÁLCULO
}

THEORETICAL FRAMEWORK AND PRACTICAL IDEAS IN THE PRODUCTION OF MULTIMEDIAL MATERIAL FOR A CALCULUS COURSE

\author{
Volumen 8, Número 1 \\ pp. 1-30
}

Este número se publicó el 30 de abril 2008

\author{
Sonia Rodríguez Soto \\ Mynor Chacón Díaz
}

La revista está indexada en los directorios:

LATINDEX $, \underline{\text { REDALYC}}, \underline{\text { IRESIE}}, \underline{\text { CLASE}}, \underline{\text { DIALNET, DOAJ, E-REVIST@S, }}$

La revista está incluida en los sitios:

REDIE, RINACE, OEI, MAESTROTECA, HUASCARAN 


\title{
BASES TEÓRICAS Y CONSIDERACIONES PRÁCTICAS EN LA ELABORACIÓN DE MATERIAL MULTIMEDIA PARA UN CURSO DE CÁLCULO

\author{
THEORETICAL FRAMEWORK AND PRACTICAL IDEAS IN THE PRODUCTION OF
} MULTIMEDIAL MATERIAL FOR A CALCULUS COURSE
}

\author{
Sonia Rodríguez Soto \\ Mynor Chacón Díaz \\ "Las personas aprenden mejor de palabras e \\ imágenes que sólo de palabras"
}

Richard E. Mayer

\begin{abstract}
Resumen: Las posibilidades para la elaboración de material multimedia han venido aumentando vertiginosamente en los últimos años, impulsadas por nuevas tecnologías informáticas y por la sensación de que facilitan el aprendizaje. La teoría de carga cognitiva de Sweller y la teoría cognitiva del aprendizaje multimedia de Mayer, que se desarrollaron y tomaron forma en la década de los noventa, han influido enormemente en el campo del diseño instruccional. Los experimentos realizados a partir de esa década arrojaron más claridad sobre el aprendizaje multimedia y han sido resumidos en una serie de principios prácticos que deben guiar tanto al diseñador novato como al experto. Este artículo resume la experiencia de los autores al diseñar material de apoyo a la enseñanza de un curso de cálculo a nivel universitario, desde la etapa de rastreo de sitios web con contenido multimedia apropiado para cursos similares, hasta la forma en que se diseñó y ajustó el material a los cánones derivados de las teorías cognitivas mencionadas. La experiencia del aprendizaje multimedia - es decir, aprender de palabras e imágenes - no es la panacea para los problemas educativos, pero bajo las condiciones apropiadas y con la población indicada resulta ser una poderosa herramienta.
\end{abstract}

Descriptores: DISEÑO INSTRUCCIONAL, MULTIMEDIA, TEORÍAS COGNITIVAS, CARGA COGNITIVA, APRENDIZAJE MULTIMEDIA

\begin{abstract}
During the last years, the possibilities for multimedia development have rapidly increased, fueled by new computer technologies and by the idea that multimedia facilitates learning. Sweller's cognitive load theory and Mayer's cognitive theory of multimedia learning, which were developed during the nineties, have influenced the field of instructional design. The experiments conducted during that decade further illuminated the process of multimedia learning and have been summarized in a series of guidelines that offer guidance to both the novice and expert designer. This paper describes the authors' experience in trying to design multimedia environments that appropriately complement the teaching process of a college calculus class, starting with the tracking of web sites with multimedia content for similar courses and finalizing with the manner in which the principles derived from cognitive theories were implemented in multimedia environments. The multimedia learning experience - learning from words and pictures - is not a panacea for all the education problems; however, under the appropriate conditions and with the right students, it turns into a powerful tool.
\end{abstract}

Key Words: INSTRUCTIONAL DESIGN, MULTIMEDIA, COGNITIVE THEORIES, COGNITIVE LOAD, MULTIMEDIA LEARNING

\footnotetext{
${ }^{1}$ Doctora en Estadística de la Universidad de Pennsylvania, Máster en Estadística, Licenciada en Matemática, ambos títulos de la Universidad de Costa Rica. Actualmente es docente de la Escuela de Matemáticas e Investigadora del Instituto de Investigación en Educación (INIE). Dirección electrónica: sonia.rodriguez@gmail.com

2 Licenciado en Matemática de la Universidad de Costa Rica. Actualmente es docente de la Escuela de Matemáticas e Investigadora del Instituto de Investigación en Educación (INIE). Dirección electrónica: minor60@gmail.com
}

Artículo recibido: 29 de febrero, 2008

Aprobado: 28 de abril, 2008 


\section{Introducción}

Los autores han estado involucrados durante años en la enseñanza de un curso de cálculo a nivel universitario que se ofrece dentro del currículo de primer año de las carreras de Ingeniería, Física y Química. La población ronda los quinientos estudiantes y la tasa de promoción oscila alrededor del 50\%. En los últimos años se ha tratado de modernizar la metodología, de manera que incorpore poco a poco el uso de software especializado y algunas tecnologías de la información y la comunicación (TIC). Uno de los cambios propuestos ha sido pasar de la clase presencial como forma exclusiva de enseñanza, a un modelo mixto que combine las lecciones en el aula con el uso de material accesible en Internet. Las lecciones presenciales se han remozado con el uso del proyector y presentaciones en pantalla, así como con la utilización de software para graficar que permite mostrar a la población estudiantil gráficos de mayor precisión que los que puede dibujar un docente en la pizarra.

Para la parte en línea del curso se eligió la plataforma Moodle como sistema de administración del aprendizaje (o LMS por su nombre en inglés, Learning Management System). Las razones de la elección de Moodle van desde lo pragmático (software libre, accesible sin costo alguno) hasta lo didáctico: el software brinda una gran cantidad de recursos, fácilmente integrables, que permiten ofrecer una variedad de elementos, tales como comunicación asincrónica (foros de discusión) y sincrónica (chat), páginas web, encuestas, quices y tareas, entre otros. En particular, Moodle cuenta con un editor básico de páginas web que permite con gran facilidad incorporar recursos de audio, animaciones o vídeo. Precisamente, para iniciar la oferta bimodal del curso y para la necesaria elaboración de materiales multimedia apropiados, los autores inscribieron un proyecto de innovación docente llamado "Sistema de Instrucción en Línea para la Enseñanza del Cálculo".

Al buscar una base teórica sólida que guiara la elaboración de multimedia, encontramos que es en el campo de las ciencias cognitivas donde se ha dado un mayor énfasis a este aspecto y que existen tres polos de investigación a nivel mundial cuyos investigadores realizan experimentos y publican regularmente en revistas científicas. Sin poder mencionar a todos los actores, los principales exponentes de las teorías cognitivas aplicadas al aprendizaje con tecnología son: 
El grupo de Richard E. Mayer y colaboradores (Universidad de California en Santa Bárbara) y Roxana Moreno (Universidad de Nuevo Mexico). El grupo de Australia con John Sweller, Slava Kalyuga y colaboradores, de la Universidad de New South Wales y finalmente, el grupo europeo que incluye en Alemania a Wolfgang Schnotz (Universidad de KoblenzLandau) y Alexander Renkl (Universidad de Friburg) y en Holanda Jeroen van Merriënboer y Fred Paas (Open University) y Huib Tabbers, de la Universidad Erasmus.

Cabe mencionar que los resultados de estos tres grupos no siempre coinciden y que aunque han avanzado mucho en ese terreno aún no logran un lenguaje común.

Por otra parte, con posiciones cautelosas o críticas ante los mitos y el abuso que se hace de las tecnologías, podemos citar a Richard Clark (Universidad de Southern California) y Robert Kozma (Center for Technology in Learning, California).

Es lamentable que los artículos publicados por estos grupos se encuentren prácticamente todos en idioma inglés, lo que posiblemente ha contribuido a que la bibliografía sobre las teorías cognitivas aplicadas al aprendizaje en ambientes con tecnología sea casi inexistente en español. Para empezar a llenar ese vacío, hemos incorporado un resumen de las principales teorías y resultados. En el presente artículo nos basamos de manera especial en las publicaciones del grupo de Mayer y Moreno. Además de la fundamentación teórica, se detallan las bases empíricas que guiaron la elaboración de los materiales multimedia puestos a disposición del estudiantado en el sitio Moodle, así como los resultados obtenidos hasta el momento.

\subsection{Hipótesis básica de trabajo y problema por resolver}

Las principales preguntas que se trató de responder con la investigación son las siguientes:

a) ¿Qué tipo de material multimedia es el más apropiado en esta etapa del desarrollo del curso de cálculo?

b) ¿Qué bases científicas sustentan el uso de materiales multimedia en la enseñanza?

c) ¿Tendrá aceptación entre estudiantes y docentes el modelo bimodal de enseñanza y el uso de Internet para la distribución de materiales y la comunicación?

En este artículo abordaremos extensamente las primeras dos preguntas y nos referiremos brevemente a la última, ya que para responder con propiedad la tercera 
interrogante se requiere de más datos, los que se obtendrán cuando el material desarrollado sea evaluado con una muestra mayor que la empleada en la prueba piloto que describiremos más adelante.

En adición a las interrogantes planteadas, partimos de una hipótesis de trabajo: los ambientes multimedia tienen el potencial de ayudar al aprendizaje de la matemática y son del agrado de la mayoría de la población estudiantil. Hay que hacer notar que la bibliografía sobre los éxitos en el uso de multimedia en la enseñanza es casi tan abundante como la que detalla sus fracasos o plantea críticas, pero la creciente importancia que día a día se manifiesta en el uso de las TICs hace imperioso el estudio científico, con datos reproducibles, sobre qué funciona mejor en el aprendizaje multimedia y cómo lo logra. La pregunta que nos planteamos por lo tanto, no es si se debe o no incorporar materiales multimedia en la enseñanza, sino más bien cómo debe hacerse, cuándo y con qué poblaciones. Una respuesta satisfactoria a estas interrogantes la proporcionan las teorías cognitivas del aprendizaje, con su corolario de recomendaciones prácticas (Sección 3).

\section{Metodología de trabajo}

Para iniciar la elaboración del material multimedia - experiencia nueva para los autores - se decidió seguir un proceso de varias etapas:

a. Determinar cuál es el estado del arte en cuanto a tecnología se refiere, ya que esta cambia con gran velocidad e influye en el tipo de materiales que se producen. Para citar un ejemplo, ya hay universidades que elaboran material para ser reproducido en iPods y el término e-learning (enseñanza basada en Internet) se amplió a i-learning (por referencia a los aparatos mencionados) y m-learning para indicar que se trata de enseñanza basada en equipos móviles (teléfonos celulares, reproductores de mp3).

b. Determinar el estado del arte respecto al tipo de materiales multimedia y los objetivos instruccionales que persiguen: ¿qué es lo que se encuentra con mayor frecuencia: páginas Web, animaciones, video?, ¿qué se busca con estos materiales: ampliar la instrucción recibida en el aula, fomentar la indagación o simplemente proponer actividades de evaluación?

c. Entre los materiales encontrados, seleccionar los que se considere más afines a las necesidades del curso.

d. Analizar los materiales seleccionados desde el punto de vista del usuario (estudiante): ¿son agradables y fáciles de usar?, ¿son fáciles de descargar o muy pesados?, ¿tienen utilidad real? 
e. Analizar los materiales desde el punto de vista del diseñador (docente): ¿son relativamente simples de producir?, ¿permiten realmente añadir un componente en línea a la enseñanza del Cálculo?

f. Estudiar las bases teóricas en las que se fundamenta el aprendizaje con material multimedia y volver a analizar los materiales seleccionados desde la óptica de dichas teorías.

g. Con base en los análisis anteriores, establecer un conjunto de reglas o recomendaciones prácticas a seguir en el diseño del material requerido.

h. Escoger programas de autoría (software) adecuados para la elaboración del material.

i. Producir material multimedia para varios tópicos del curso.

j. Hacer una prueba piloto del material elaborado, en un grupo reducido de estudiantes y analizar la experiencia antes de hacer una prueba más estructurada con la población general.

Las dos primeras etapas se llevaron a cabo simultáneamente, mucho antes de comenzar a elaborar el material propiamente dicho. El trabajo consistió en una búsqueda intensa de material multimedia tanto en Internet como en CDs. Esta actividad de búsqueda toma su tiempo, en nuestro caso duró alrededor de seis meses. La idea era conocer el estado del arte en cuanto a la producción de material multimedia para luego discernir qué era lo más apropiado para el curso en cuestión, tanto desde el punto de vista de las necesidades educativas como de las limitaciones tecnológicas, económicas y humanas.

El proceso de búsqueda se circunscribió a material relacionado con matemática, por las dificultades y características propias de la materia. Además, se seleccionaron únicamente los de nivel de educación secundaria y universitaria, ya que el software diseñado para niños tiene características muy particulares que no necesariamente son indicadas para poblaciones de estudiantes mayores. En cuanto a tecnología, se descartó desde el inicio el uso de material diseñado para aparatos móviles, ya que por el momento estos no son de uso regular en la población universitaria y además limitan bastante el tipo de materiales que se puede producir: las pantallas son demasiado pequeñas para mostrar texto, ecuaciones y gráficos simultáneamente. 


\subsection{Estado del arte: tipo de material encontrado}

La primera sorpresa al empezar la búsqueda en Internet, fue la poca cantidad de material multimedia para matemática a nivel superior que se encuentra. Aun en universidades que se precian de contar con un campus virtual de primera, la mayor parte del material ofrecido a sus estudiantes consiste exclusivamente de textos, sean estos archivos Word o PDF, o bien páginas Web. Vale aquí indicar que la definición de la palabra multimedia la hemos dejado a propósito para una sección posterior, es decir, estamos utilizando más bien el concepto intuitivo del término.

Además de textos, encontramos sitios que cuentan con applets, que son pequeños programas escritos en Java y que usualmente proporcionan cierto grado de interacción al usuario. Los applets son muy populares por su pequeño tamaño (medido en bytes), por ser fáciles de incrustar en páginas Web y por la seguridad que ofrecen, ya que no pueden acceder los recursos del computador local. También localizamos material que incorporaba animaciones, escrito la mayor parte de las veces en Flash (archivos SWF) o en Director y por último, encontramos una muy pequeña cantidad de sitios que incluían videos, usualmente archivos tipo AVI o MOV.

En cuanto al objetivo que se persigue con los materiales ofrecidos en sitios Web, este es muy variado. Algunos textos desarrollan una parte de la teoría, otros son simples listas de ejercicios a resolver o bien ejemplos con solución. Los applets generalmente forman parte de actividades de indagación que incluyen el uso de graficadores o calculadoras. En otros sitios se encuentran quices interactivos que permiten la autoevaluación y finalmente, los videos pueden contener explicaciones teóricas o ejemplos resueltos. Las simulaciones y juegos interactivos en matemática a nivel universitario son muy escasos.

\subsection{Análisis inicial del material seleccionado}

En esta sección enumeramos las impresiones iniciales derivadas del análisis de los diversos materiales localizados. Debemos hacer notar que el nombre o dirección de los sitios Web visitados no se incluye, ya que así podemos referirnos con total libertad al trabajo dedicado y pionero de muchos autores. La idea fundamental de este artículo no es hacer críticas o señalar errores y deficiencias encontrados en el material elaborado por otros, sino más bien detallar, de qué manera los aciertos y las deficiencias percibidas influyeron en el diseño y 
puesta en práctica al elaborar nuestro propio material. En resumen, se trata de no caer en los mismos errores detectados.

El primer análisis del material encontrado se realizó de manera subjetiva, basándonos únicamente en nuestra experiencia como docentes y utilizando el sentido común. Sin embargo, produjo resultados que concordaron en forma sorprendente con los predicados de las principales teorías cognitivas que analizan e informan el diseño instruccional de material multimedia. El estudio de teorías tales como la Teoría de Carga Cognitiva de Sweller (Sweller, van Merrienboer y Paas, 1998; Sweller, 2005 a) y la Teoría Cognitiva del Aprendizaje Multimedia de Richard E. Mayer (Mayer, 2005; Moreno y Mayer, 1999; Mayer y Moreno, 1998) nos proporcionaron posteriormente las herramientas para hacer un segundo análisis, esta vez bajo la lupa objetiva de teorías cognitivas que han sido sometidas a la experimentación para validar sus postulados. Esta segunda revisión permitió afinar y mejorar algunas de las conclusiones prácticas a las que ya habíamos llegado de manera intuitiva y nos proporcionó una base sólida para el desarrollo del material multimedia. A continuación desglosamos las ventajas o desventajas que percibimos en cada tipo de material.

\subsubsection{Archivos de texto y páginas Web sin animaciones}

Una decisión que se tomó desde el inicio fue que el material que se ofreciera en la plataforma Moodle no debía consistir exclusivamente de textos. No pretendemos negar el poder de Internet como un sitio donde la distribución de material escrito se ha puesto al alcance de todos: esa es una de las grandes maravillas de las TICs. Sin embargo, creemos que limitar un medio tan versátil a cumplir de manera imperfecta las funciones de un libro, es un desperdicio de recursos. Por este motivo descartamos del análisis todo tipo de documentos aptos para ser distribuidos en forma impresa. Una vez establecido esto, el paso siguiente fue revisar los demás materiales en busca de alternativas viables.

\subsubsection{Applets}

No nos agradó la forma como se utiliza la mayoría de los applets encontrados. Esto no se debe a una deficiencia inherente al software, sino a la manera en que se implementa. En general, este tipo de archivos cuenta con algún control o deslizador que permite al usuario variar ciertos aspectos tales como color, forma de los gráficos o valor de los parámetros involucrados. En general, cuando se presentan gráficas, la calidad estética es pobre. Su principal función podemos definirla como software de exploración; es decir, los applets se 
prestan para diseñar materiales donde cada estudiante puede descubrir fácilmente qué sucede si varía ciertas condiciones como las mencionadas. Desde el punto de vista del profesorado, los applets tienen la desventaja que para elaborarlos se requiere aprender a programarlos en Java, cosa que no es trivial. Por lo tanto decidimos no utilizar applets, al menos por el momento, ya que hay otras alternativas más simples de implementar, al alcance de la mano y con mayor calidad estética, si es que se quiere utilizar actividades de exploración.

\subsubsection{Animaciones sin audio}

Luego se analizaron sitios Web relacionados con temas de matemática de nivel secundario o universitario que combinaban texto con animaciones. Algunos de estos sitios tienen como población meta los estudiantes y otros se dirigen más bien a los docentes. En algunos la calidad de las animaciones es de primera, usualmente elaboradas en Flash. Sin embargo, no nos agradaron por una sola razón: no tenían sonido. Al inicio no es tan molesto, pero después de algunos minutos de ver animaciones en silencio, la sensación de aburrimiento y desorientación es frecuente. Nosotros los llamamos "sitios mudos" y contribuyeron definitivamente a tomar una decisión fundamental para la elaboración del material: si utilizamos explicaciones con animación, estas deberán necesariamente incluir audio. De lo contrario, creemos que las animaciones "mudas" pueden ser sustituidas con ventaja por buen material escrito, salvo casos de excepción como pueden ser pequeñas animaciones de pocos segundos de duración. Para efectos del curso de cálculo, con una animación pequeña se puede mostrar por ejemplo la propiedad reflexiva de la parábola.

\subsubsection{Sitios con animación y audio}

Finalmente encontramos dos sitios Web donde se explicaban temas de matemática a nivel universitario - ambos utilizaban audio y animación - los vamos a llamar sitio A y sitio B. En el sitio A se ofrecía una cantidad impresionante de videos que el estudiante podía ver en el sitio o descargar en su computador. Cada video explica la solución de un problema específico, la cual ha sido escrita de antemano con ayuda de algún software. El autor describe la solución, a medida que va señalando con ayuda del cursor la parte a la cual él se está refiriendo. El movimiento del cursor se grabó simultáneamente con el audio, con ayuda de software de captura dinámica de pantalla. 
Se debe señalar que existen varios programas de captura dinámica, algunos gratuitos, pero usualmente los archivos que producen son de un tamaño excesivo. En este sitio nos llamó la atención que el peso de los archivos se mantenía dentro de límites razonables, es decir, menos de $2 \mathrm{MB}$ por minuto de transmisión. El tipo de material ofrecido en este sitio marcó varias de las decisiones tomadas desde el inicio. En primer lugar nos agradó mucho el hecho que la solución estuviera escrita de antemano. Esto contribuye a la nitidez de la presentación y al mismo tiempo, la solución del problema se convierte en una especie de guión para el locutor, quien debe ir comentando o ampliando la explicación conforme avanzan los pasos seguidos en la solución. A pesar de que los puntos positivos de este material son muchos, hay un detalle muy inconveniente: el tener que seguir y ubicar con la vista dónde se encuentra el cursor se convierte en algo que distrae, pues hay momentos en que se pierde el hilo de la explicación al concentrar la atención en el movimiento del cursor. De aquí viene la siguiente decisión tomada: en todo el material se utilizará otro tipo de señalización que no consista en algo tan pequeño como un cursor y que sin mayor esfuerzo oriente al usuario a la parte de la pantalla que debe mirar.

Desde el punto de vista del nivel académico, los ejemplos seleccionados en el sitio A nos parecieron muy adecuados: no son triviales, lo que haría aburrida y de poca utilidad la presentación, ni son tan difíciles que requieran de una explicación muy minuciosa y larga. Además, como mencionamos anteriormente, la gran cantidad de ejemplos ofrecidos es un punto a favor. Por desgracia, la última vez que revisamos el sitio, la mayor parte del material había desaparecido de Internet debido a que el docente se pensionó.

El sitio B muestra mayor calidad técnica, fue elaborado muy probablemente por un equipo de profesionales en multimedia, al contrario del sitio A cuya elaboración recayó directamente en un solo docente. A pesar de esto, el material en el sitio B muestra fallas atribuibles al desconocimiento de las normas prácticas de diseño instruccional derivadas de las teorías cognitivas. Un ejemplo de esto es que la pantalla está dividida en dos partes, en algunos momentos en ambas se muestra texto y hay una narración que describe la solución de un ejercicio. Como veremos más adelante, esto es una trasgresión evidente al principio de la atención dividida. El problema más evidente se produce cuando la narración llega al final de la pantalla: en este momento hay un desplazamiento vertical automático (scroll en inglés) del texto en lugar de presentar una pantalla nueva. Este movimiento escapa del control del usuario y produce una sensación parecida a leer en un coche en marcha: es una sensación 
incluso de malestar físico. Otra desventaja consiste en que hay momentos donde la narración se limita a repetir lo escrito en la pantalla, volviendo redundante a uno de los dos. No es de sorprender entonces, que tanto Mayer como Sweller, en lo que ambos llaman Principio de Redundancia, establezcan que esta práctica no es recomendable (Mayer, 2005; Sweller, 2005 b).

En cuanto a la parte metodológica, se presentan explicaciones teóricas muy resumidas y ejemplos resueltos de nivel muy elemental. La principal deficiencia metodológica es la pobreza, tanto en cantidad como en calidad de los ejemplos resueltos. La mayor fortaleza es el diseño gráfico que se nota en la interfase y en la utilización de recursos de programación, ya que el mismo efecto de desplazamiento vertical que criticamos fue programado con cuidado.

\subsubsection{Lecciones grabadas en video}

Finalmente, encontramos otros sitios con videos donde un docente va explicando a medida que escribe, ya sea en una pizarra, en una hoja de papel o en una computadora tipo Tablet. La calidad es muy variada, desde lecciones de aproximadamente una hora puestas en Internet sin ningún tipo de post-edición, hasta otras donde es evidente el empleo de más de una cámara y trabajo de edición hecho por profesionales.

Consideramos que este tipo de material puede ser muy útil, sobre todo si la idea es proporcionar una lección completa. Aunque hemos albergado por largo tiempo la idea de implementar clases enteras en video, se desestimó su uso por el momento. Sin embargo, los videos bajados de Internet serán de utilidad en un futuro, cuando podamos avanzar a una segunda etapa en la modernización del curso y el análisis de este material nos pueda guiar en la elaboración de nuestros propios videos.

\subsection{Necesidades específicas del curso}

Reconocemos que muchos de los tipos de material encontrado pueden tener una gran utilidad en la enseñanza y aprendizaje del Cálculo. Sin embargo, las necesidades de la primera etapa de implementación de un componente bimodal eran muy concretas: necesitábamos material que sirviera de complemento a las lecciones presenciales y que permitiera al estudiante repasar ciertos temas por su cuenta. Se decidió que no se presentaría materia nueva ni teoría, sino más bien ejemplos resueltos, presentados de manera similar a los encontrados en el sitio A. Además se quería que los ejercicios tuvieran 
un nivel medio, ya que ejemplos básicos se le presentan al estudiante en el texto elaborado para el curso. Por el contrario, ejemplos de solución más elaborada y compleja se dejan de tarea y pueden revisarse en clase.

Por otra parte, se había establecido el requisito de que la presentación tuviese animación y narración simultánea, lo que conlleva a decisiones importantes en cuanto al software requerido. Creemos que la parte computacional, tanto en lo referente a software para animación o edición de video, así como la edición de audio, son merecedoras de un análisis más extenso en un próximo artículo, ya que en nuestro medio la elaboración de este tipo de material aún es incipiente y compartir las experiencias es una manera de aprender y de mejorar.

Finalmente, como no contamos con diseñadores profesionales, esto limita el software utilizado a aquellos accesibles tanto desde el punto de vista económico, como desde la perspectiva de la curva de aprendizaje requerida para utilizarlos. Aún así, tuvimos que aprender a utilizar alrededor de siete programas de producción de animaciones y captura de pantalla; iniciamos el aprendizaje de un software especializado en edición de video y nos familiarizamos con un programa de edición de audio. Existen muchos otros programas que quisiéramos incorporar al arsenal de herramientas tecnológicas, pero la limitante de tiempo para aprender a utilizarlos es un factor importante.

\section{Fundamentación científica del aprendizaje multimedia}

Las bases teóricas que justifican el uso de multimedia en la enseñanza incluyen numerosos conceptos y teorías, algunas de las cuales serán mencionadas a continuación. Hay varios enfoques que pueden adoptarse al estudiar el fenómeno del aprendizaje multimedia, pero se escogió el marco de las teorías cognitivas debido a que ofrecen una explicación muy intuitiva del porqué los ambientes multimedia pueden favorecer el aprendizaje y además porque estas teorías han sido sometidas a gran cantidad de experimentos para demostrar los principios que postulan.

En primer lugar, debemos precisar el significado de algunos términos que utilizaremos en el presente trabajo, empezando por la palabra multimedia. 


\section{1. ¿Qué entendemos por multimedia?}

El término multimedia ha ido cambiando su significado con el paso de los años y aún hoy en día no todo el mundo se refiere a lo mismo cuando utiliza dicha palabra. Del latín multum y medium, se debe entender como múltiples medios de presentar y procesar información, entre los cuales podemos citar texto impreso, imágenes estáticas o con animación, audio (música, sonidos especiales o narración), video e interactividad. Por supuesto, lo que se incluya dentro de "medios" debe irse adaptando conforme nuevas tecnologías emergen. En un artículo de 1981 - antes de que las PCs revolucionaran lo que entendemos por "computadoras" - se alaba el uso de multimedia en cursos de extensión y se menciona el uso de varios medios: correo terrestre, televisión o instrucción por teléfono (Kristiansson, 1981). ¡Difícilmente son estos los medios que nos vienen a la mente cuando decimos multimedia en la actualidad! Sin embargo, todos ellos tienen sus equivalentes modernos: email, video y chat. En sentido estricto, cualquier presentación que incluya los elementos citados puede considerarse multimedia y eso abarca los libros ilustrados con imágenes, una presentación tipo Power Point donde el presentador hace la narración en vivo o la clase de matemática dictada por un docente que utiliza elementos visuales como la pizarra con fórmulas y el gráfico de una función (imagen estática), y además, de manera simultánea explica el procedimiento (narración, modalidad aural). Debido a que el término es tan amplio, muchos autores delimitan la investigación sobre multimedia a materiales con soporte digital. En el presente trabajo también nos circunscribimos al análisis de material digital, aunque esto no significa que restemos importancia al uso de otros medios (televisión, radio, material en VHS, presentaciones en vivo) como herramientas para el aprendizaje.

Para Richard Mayer (Mayer, 2005), multimedia significa presentar simultáneamente palabras (habladas o escritas) e imágenes (gráficos, fotografías, animaciones, video). Considera que se puede caracterizar el material multimedia desde 3 puntos de vista: a) la tecnología (¿qué aparatos se utilizan?, pantalla del monitor, proyectores, parlantes?, b) el modo de presentación (verbal o pictórico) y c) la modalidad sensorial (visual o auditiva). Él rechaza el análisis basado exclusivamente en la parte tecnológica y escoge el modo de presentación, con alguna influencia de la modalidad sensorial.

El siguiente esquema muestra las distintas formas que las palabras y las imágenes pueden tomar cuando hablamos de multimedia. 




Figura 1: Posibles combinaciones entre modo $y$ modalidad en el material multimedia.

Además de darnos una definición práctica del término multimedia, Mayer distingue entre aprendizaje multimedia (construcción de modelos mentales basados en las imágenes y palabras) y la instrucción multimedia o ambientes de aprendizaje multimedia (utilización de imágenes y palabras con el fin de promover el aprendizaje).

\subsection{Arquitectura Cognitiva}

Entre las preguntas que más han inquietado a los grandes pensadores desde hace siglos, se encuentran la naturaleza de la materia, el origen del universo y el funcionamiento de la mente humana. Hasta hace muy poco, el conocimiento de la mente - y del pensamiento y el aprendizaje que ella hace posibles -- permanecía elusivo. (National Research Council, 2000). La situación en la actualidad es muy diferente, principalmente con el auge de las teorías cognitivas y neurociencias, que permiten un mejor conocimiento de la estructura y funcionamiento de la herramienta más poderosa de la humanidad: la mente. Por arquitectura cognitiva entendemos tanto las características como las relaciones entre memoria de trabajo y memoria de largo plazo. Para Sweller (2005 a), los seres humanos carecemos de un ente director en la memoria de corto plazo (i.e. el ejecutivo central) y debemos suplir esta deficiencia mediante los esquemas que guardan la información organizada en la memoria de largo plazo. 


\section{Memoria de trabajo (memoria operacional)}

La memoria de trabajo u operacional, es de capacidad muy limitada. Este concepto es una extensión de la memoria de corto plazo (o memoria inmediata) planteado por Miller (1956). El término "working memory" en inglés, ha sido traducido al español como memoria de trabajo y memoria operativa, aunque no necesariamente las dos acepciones significan lo mismo.

Según Etchepareborda y Abad-Mas (2005), la memoria se puede clasificar en inmediata, mediata y de largo plazo o diferida, señalando que "la memoria a corto plazo, memoria mediata, memoria de trabajo (MT) o funcional, es la que guarda y procesa durante breve tiempo la información que viene de los registros sensoriales y actúa sobre ellos y también sobre otros". En su trabajo los autores describen distintos modelos de funcionamiento de la MT, entre otros el propuesto inicialmente por Baddeley y Hitch en 1974 (citado por Baddeley, 2002).

Este modelo se aparta del antiguo concepto simplista de almacenamiento temporal como función principal de la MT y le otorga mayor importancia a los procesos que ocurren en ella. Para esto se introducen tres componentes que se muestran en la Figura 2.



Figura 2: Memoria operacional como un sistema de tres componentes

El ejecutivo central es un controlador de capacidad limitada que tiene dos componentes esclavos: el bucle articulatorio encargado de procesar la información verbal y acústica y la agenda visuoespacial que procesa las imágenes y la información espacial, sirviendo de interfase entre ambas. Sin embargo, este modelo ha ido evolucionando en los últimos treinta años y el mismo Baddeley, en el 2005 plantea una revisión más elaborada y que incluye un nuevo componente, el buffer episódico. En este modelo revisado se hace más explícita la interacción entre memoria de trabajo y memoria de largo plazo. Es interesante mencionar 
que a pesar de que el concepto de memoria operativa o de trabajo tiene sus raíces en la psicología cognitiva, ha sido adoptado e integrado en las neurociencias. Arteaga y Pimienta (2006) hacen una revisión de la memoria operativa desde el punto de vista de la neurociencia cognitiva, indicando incluso que esta se localiza en la parte prefrontal del cerebro. Por su parte, otro grupo de investigadores logra incluso detectar el lugar preciso del cerebro humano donde se produce la integración de la información visual y auditiva, ubicándolo en el lóbulo parietal superior (Molholm et al, 2006).

\subsection{Memoria a largo plazo}

La memoria de largo plazo (MLP) es el lugar donde se almacena el conocimiento. Tiene una capacidad prácticamente ilimitada, como se ha logrado demostrar estudiando a los grandes maestros de ajedrez. La función de la MLP en cuanto al aprendizaje es vital. Según Sweller (2005 a), "el aprendizaje es una alteración en la memoria de largo plazo. Si nada ha cambiado en la memoria de largo plazo, nada se ha aprendido". Como consecuencia, la meta principal de la instrucción se convierte en la promoción de cambios o alteraciones adecuadas en la MLP.

Hay que señalar, sin embargo, que no todos los aprendizajes son iguales: se puede aprender mecánica o memorísticamente y por el contrario se puede aprender con comprensión o significativamente. Ambos aprendizajes producen cambios en la MLP. La diferencia básica entre ambos tipos de aprendizaje consiste en la cantidad y calidad de los esquemas acumulados en la MLP. Por esquemas se entiende las construcciones cognitivas que permiten organizar distintos elementos de información y los categorizan en un solo elemento (Sweller, 2005 a). Estos esquemas funcionan como organizadores de la nueva información y por lo tanto facilitan el aprendizaje: a mayor cantidad de esquemas y a mayor complejidad de estos, el aprendizaje se vuelve más natural. Los esquemas a su vez pueden organizarse en esquemas más complejos, de una manera jerárquica.

\subsection{Teoría de la carga cognitiva}

La teoría de carga cognitiva de Sweller (Paas, F., Renkel, A. y Sweller, J., 2004; Sweller, J., van Merrienboer, J. y Paas, F., 1998; Sweller, 2005 a) se basa en las características de la estructura cognitiva ya mencionadas. En particular, se enfatiza en las limitaciones de la memoria de trabajo y se establece que el proceso de recibir, organizar e incorporar nueva información supone una carga en el sistema; a esto se le llama carga cognitiva. Esta última se clasifica en tres tipos diferentes, como se indica a continuación. 


\section{Carga intrínseca}

Es la carga ocasionada por la complejidad misma de lo que se quiere resolver o aprender. No puede ser manipulada o reducida por el diseño instruccional. Para ilustrar el concepto con un ejemplo citado a menudo, podemos decir que aprender unas pocas palabras en un nuevo idioma representa una carga intrínseca baja, mientras que tratar de comprender una conferencia dada en una lengua poco familiar representa una carga intrínseca altísima.

\section{Carga extrínseca}

Es la parte de la carga cognitiva que debe reducirse mediante un buen diseño instruccional, ya que es irrelevante para el aprendizaje. Como ejemplo, si en una presentación multimedia existen efectos de sonido o animaciones muy rápidas, eso produce una carga cognitiva que interfiere con el aprendizaje y que no tiene ninguna razón de ser: un mejor diseño puede reducir o eliminar este problema. Inclusive en una lección tradicional, el docente puede aumentar la carga extrínseca, por ejemplo cuando escribe en desorden en la pizarra o cuando no se expresa claramente al explicar un nuevo concepto.

\section{Carga relevante}

Esta es la carga que contribuye al aprendizaje y puede ser influenciada por un diseño adecuado. Todas las acciones que contribuyan a la formación de esquemas mentales, tales como el uso de organizadores gráficos, mapas conceptuales y similares contribuyen a la carga relevante y por ende conducen a un mejor aprendizaje.

En conclusión, al diseñar material multimedia, o al involucrarse en cualquier otra actividad instruccional, hay que mantener un delicado balance: reducir al máximo la carga extrínseca y al mismo tiempo velar por una adecuada carga relevante para que el total de la carga no se convierta en sobrecarga e interfiera con el aprendizaje que se quiere facilitar.

\subsection{Teoría cognitiva del aprendizaje multimedia}

La teoría cognitiva del aprendizaje multimedia de Mayer (Mayer, 2005; Moreno, R. y Mayer, R. E., 2000; Moreno, R. y Mayer, R. E., 1999; Mayer, R. E. y Moreno, R., 1998) tiene sus raíces en la teoría de la codificación dual de Paivio (2006). Se refiere al proceso de recepción de nueva información en los canales auditivo y visual, al procesamiento en la memoria de corto plazo, y su posterior integración con conocimientos previos en la memoria a largo plazo, como se observa en la Figura 3. 


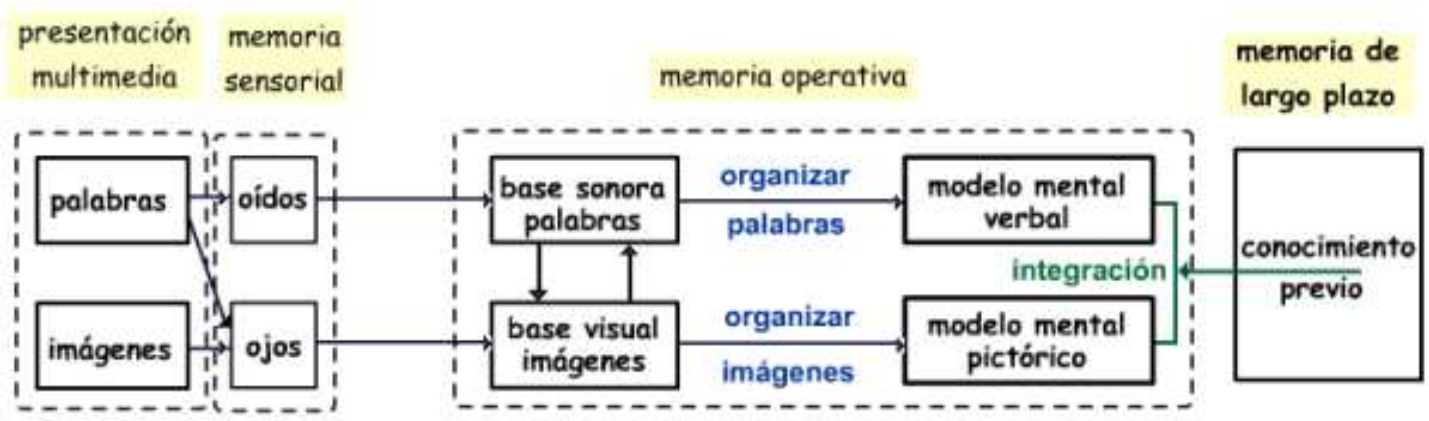

Figura 3: modelo cognitivo del aprendizaje multimedia (adaptado de Mayer, 2005)

En suma, la teoría cognitiva del aprendizaje multimedia trata de explicar de qué manera el aprendizaje es facilitado o inhibido por la base multimedial de la información. Mediante cuidadosos experimentos se procura dilucidar cuándo y por qué funciona un determinado tipo de material. Los resultados se van acumulando en una serie de principios que facilitan al diseñador instruccional la tarea de producción. Si una imagen vale más que mil palabras, la Figura 3 es un buen ejemplo de ello. Al enfrentarse a una presentación multimedia, la información entra por los canales auditivo y visual. Las palabras y las imágenes se seleccionan y organizan en la memoria de corto plazo, donde también interactúan con el conocimiento previo que se recupera de la memoria de largo plazo. Si el aprendizaje es exitoso, nuevos esquemas se forman e integran con los anteriores y de nuevo se almacenan en la memoria de largo plazo hasta que el aprendiz vuelva a necesitarlos. Esta figura resume también de manera gráfica las premisas en que descansa la teoría cognitiva del aprendizaje multimedia: a) Canales duales (los seres humanos poseen canales separados para procesar la información visual y auditiva); b) Capacidad limitada (la información que se puede procesar en cada canal es limitada) y c) Procesamiento activo (los seres humanos procesan activamente la información, organizando palabras e imágenes e integrando los respectivos modelos mentales).

\subsection{Principios de diseño instruccional derivados de la teoría de carga cognitiva}

La Teoría de carga cognitiva y la Teoría cognitiva del aprendizaje multimedia no solo presentan una base teórica coherente que permite comprender los procesos que tienen lugar en la mente humana cuando ocurre un aprendizaje, sino que además han sometido a experimentación científica sus postulados. Esos experimentos han establecido una serie de normas que Mayer y su grupo llama principios y que Sweller y otros investigadores han 
denominado efectos en varias de sus publicaciones. Nos parece más ilustrativo el término efecto, porque evoca la influencia que ejerce el ambiente multimedia en el aprendizaje y porque no tiene la connotación de norma general que viene a la mente con la palabra principio. El término principio, según el diccionario, se puede definir como "Una generalización básica que es aceptada como cierta y que puede ser usada como base para el razonamiento o conducta" (Clark, 2005). Las normas o principios que se describen a continuación, tienen muchas excepciones y no son verdades absolutas; sin embargo, el término principio ha venido siendo utilizado con mayor frecuencia en la literatura de las ciencias cognitivas y es el que emplean los autores de capítulos del Manual de Cambridge del Aprendizaje Multimedia (Mayer, 2005), así que también emplearemos el término.

Los principios están muy relacionados entre sí, hasta el punto que resulta difícil tratarlos por separado, pues sus efectos se entremezclan. Han sido definidos en numerosos trabajos de Mayer, Sweller y Moreno, entre otros, y se han ido refinando en los últimos diez años. Hoy en día han sido estudiados y documentados al menos veinticinco principios. Mayer (2005) en su Manual los clasifica en básicos y avanzados. De este manual tomamos algunas de las definiciones de los principios básicos que consideramos han influido más en el diseño de nuestro material.

\section{Principio de multimedia}

Es el fundamental ya que sobre este descansa la justificación del empleo de multimedia en la enseñanza, y ya lo citamos en el epígrafe: "Las personas aprenden mejor de palabras e imágenes que solo de palabras". Esta premisa, engañosamente simple, tiene sus raíces siglos atrás. Específicamente en matemática, siempre se ha entendido la importancia del uso de imágenes para facilitar la comprensión. El vínculo en la siguiente imagen miniatura muestra la reproducción digital del manuscrito más antiguo que se conserva (escrito en el año 888 en Constantinopla) de los Elementos de Euclides, y cuya versión digital ha sido puesta a servicio del público por la Biblioteca sin Paredes. (http://librarieswithoutwalls.orgh).

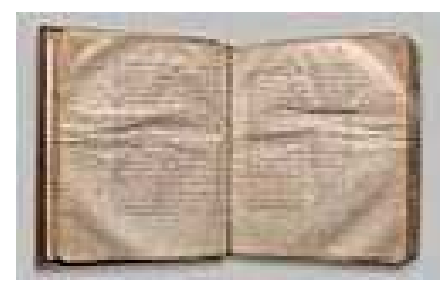


Si observamos las imágenes ampliadas, se observa cómo al lado del texto se incluyen imágenes que son necesarias para la mejor comprensión de las demostraciones. De hecho la figura de la izquierda es una representación gráfica del teorema de Pitágoras.

El término principio de multimedia ha venido evolucionando. Mayer y Moreno se referían a este como principio de representación múltiple y como efecto multimedia (Mayer y Moreno, 1998), pero en esencia la noción es la misma: es mejor presentar una explicación con palabras e imágenes que solamente con palabras. En ese mismo trabajo se describen los experimentos que lo comprueban: después de estudiar el funcionamiento de un inflador de bicicletas mediante una presentación multimedia, los estudiantes que tuvieron acceso a una animación con explicación narrada obtuvieron mejores resultados en pruebas posteriores que aquellos que solo pudieron escuchar la narración. Similarmente, los estudiantes que leyeron la explicación en un texto con imágenes al lado salieron mejor en las pruebas que aquellos que solo tuvieron acceso al texto sin imágenes (Figura 4).

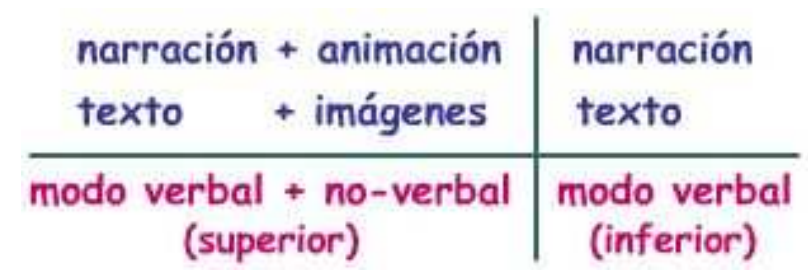

Figura 4: Experimentos sobre el principio de multimedia

El principio multimedia "concuerda con la teoría del aprendizaje multimedia, ya que los estudiantes a quienes se les da explicaciones multimedia son capaces de construir dos diferentes representaciones mentales - un modelo verbal y un modelo visual - y construyen conexiones entre ambos" (Mayer y Moreno, 1998, p. 3).

Sin embargo, no debemos confundirnos con la simpleza del principio multimedia: las palabras y las imágenes pueden tomar diversas formas, como se muestra en el esquema de la Figura 1. Las distintas maneras de mezclar los elementos de dicho esquema dan lugar a varios de los principios siguientes, ya que no todas las combinaciones son de igual utilidad en la enseñanza y por el contrario, algunas más bien interfieren con el aprendizaje. 


\section{Principio de modalidad}

El principio descrito en la sección anterior - principio multimedia - se refiere básicamente al modo en que se presenta la información y se puede resumir diciendo que es mejor que esta se presente en ambos modos: verbal y pictórico. En experimentos subsiguientes, Moreno y Mayer (2000) se preguntaron si el resultado superior obtenido por los estudiantes en los experimentos descritos anteriormente, cuando se les presentó información verbal y no verbal en forma simultánea, se debía únicamente al principio multimedia o si por el contrario existía además un efecto ligado a la modalidad; es decir, si el hecho de presentar información en la modalidad visual o aural tenía repercusiones. Al combinar ambos modos se utilizan los dos canales de la memoria operativa de manera simultánea y se podría asumir que esto fue la causa de que el aprendizaje resultara más profundo. Para poder separar el efecto multimedia de un posible efecto de modalidad, Moreno y Mayer (2000) diseñaron varios experimentos en los que se somete a los estudiantes a seis diferentes situaciones de aprendizaje, resumidas en la siguiente figura:

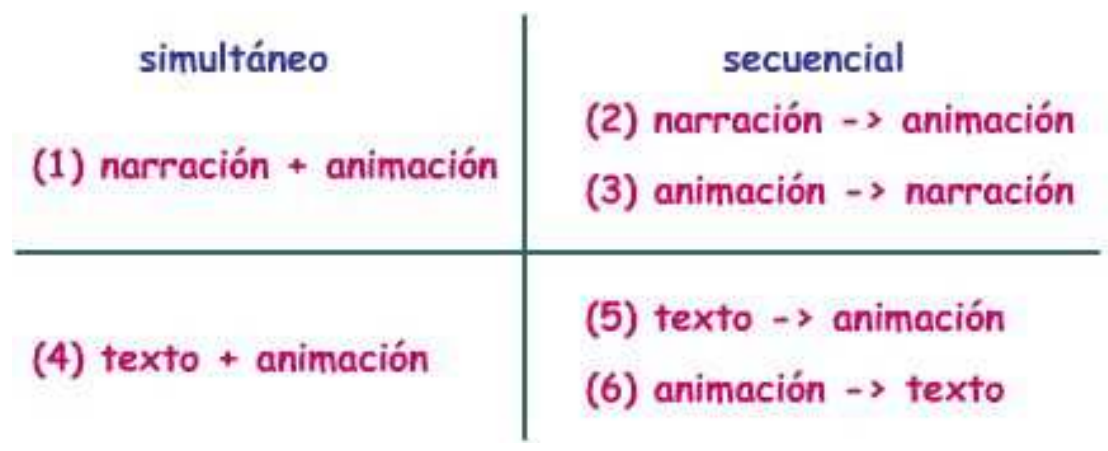

Figura 5: determinación del principio de modalidad

Debe aclararse que el modo no verbal se mantiene constante pues se utiliza la misma animación en todos los casos, mientras que es en el modo verbal que se varía la modalidad: se utiliza una narración (modalidad auditiva) o un texto en pantalla (modalidad visual). En (1), (2) y (3) de la Figura 5, la modalidad es auditiva, mientras que en (4), (5) y (6) es visual. Hay que notar que en los seis casos se respeta el principio multimedia pues los dos modos están presentes.

Los resultados fueron concluyentes: en las pruebas donde se utilizó narración, es decir, las situaciones (1) a (3), los estudiantes obtuvieron resultados significativamente más altos que cuando se empleó texto, o sea, los casos (4) a (6), sin importar si los dos elementos se 
presentaban de manera simultánea o en secuencia. Por otro lado, no hubo diferencia significativa en los resultados obtenidos en cada grupo de modalidad. Esto permitió considerar el efecto de modalidad como un principio por derecho propio, lo que concuerda con otros experimentos realizados por Mousavi, Low y Sweller (1995), citado por Moreno y Mayer (2000).

Se podría resumir el principio multimedia y el modalidad diciendo que se aprende mejor con palabras e imágenes, sobre todo cuando las palabras son narradas.

\section{Principio de coherencia}

Algunos autores incorporan en el material multimedia efectos de sonido o animaciones con la intención de hacerlo más llamativo y captar la atención de los estudiantes.

Según la teoría de carga cognitiva, al inicio la información se procesa separadamente por los canales auditivo y visual, ambos con capacidad limitada. En este sentido, Moreno y Mayer (2000) diseñaron un experimento para determinar si la adición de música o sonidos ambientales en una presentación multimedia favorece o perjudica el aprendizaje de los estudiantes. De acuerdo con la teoría de carga cognitiva, es probable que se produzca una sobrecarga en el canal auditivo al tratar de escuchar música o sonido además de la narración, cosa que pudo comprobarse en dicho experimento. La prueba consistió en presentar a setenta y cinco estudiantes universitarios una animación con narración con las siguientes alternativas para el modo verbal: a) Al primer grupo $(\mathrm{N})$ se le presentó solamente la narración, b) Un segundo grupo (NA) tuvo narración junto con sonidos ambientales, c) al tercer grupo (NM) se le presentó la narración con música y d) el último grupo (NAM) tuvo acceso a la narración junto a sonidos ambientales y música. En la presentación se explica en pocos minutos la formación de los rayos y los sonidos ambientales se refieren al fenómeno estudiado.

En el test de transferencia se comprobó que:

- Los estudiantes tuvieron resultados más bajos en los grupos en que se utilizó música.

- La presencia o ausencia de sonidos ambientales no produjo diferencias significativas.

-Los resultados más bajos los obtuvieron los estudiantes del grupo que escuchó la narración junto con música y sonidos ambientales. 
Posteriormente, otras evaluaciones de transferencia comprobaron el último punto: el grupo (NAM) obtuvo consistentemente resultados más bajos que cualquiera de los otros tres grupos.

Los resultados sugieren que hubo sobrecarga auditiva al añadir música, puesto que se trata de material no relevante que compite con la narración en la asignación de recursos cognitivos. Los sonidos ambientales no interfirieron con el aprendizaje al estar coordinados con la narración. Como conclusión, podemos inferir que no debe añadirse material auditivo, a menos que contribuya a hacer más inteligible la explicación. Cabe señalar que también se puede producir sobrecarga en el canal visual, por lo que tampoco es recomendable la utilización de material visual superfluo.

Entonces, se deduce el siguiente principio empírico, llamado principio de coherencia, el cual establece que "las personas aprenden más profundamente cuando se excluyen sonidos o imágenes irrelevantes a lo que se está tratando de explicar".

\section{Principio de Redundancia}

En otros experimentos reportados también por Moreno y Mayer (2000, 2001), los autores tratan de dilucidar si la información verbal redundante facilita el aprendizaje o no. En este contexto, por información verbal redundante se entiende que las palabras aparecen simultáneamente como texto en pantalla y como narración. Participaron sesenta y nueve estudiantes universitarios, divididos en cuatro grupos. Todos los grupos vieron la misma animación. En dos de ellos, además de la animación, simultáneamente escucharon la narración que describía la formación de los rayos. En los otros dos grupos la narración se produjo secuencialmente, es decir después de ver la animación. Además, para obtener el efecto de redundancia, se presentó texto en la pantalla en uno de los grupos de tratamiento simultáneo y en uno de tratamiento secuencial. El diseño queda más claro en la Figura 6.

\begin{tabular}{|l|c|c|}
\hline & simultáneo & secuencial \\
\hline sin redundancia & animación + narración & animación - > narración \\
\hline con redundancia & animación + narración + texto & animación - > narración + texto \\
\hline
\end{tabular}

Figura 6: diseño 2x2 de los experimentos 
Para analizar los resultados los investigadores realizaron un análisis de variancia en dos componentes siendo la información verbal redundante el factor a analizar. El análisis de variancia mostró una interacción significativa entre redundancia y orden de presentación, de manera que cuando la narración fue secuencial, la población estudiantil con información verbal redundante (animación -> narración + texto) obtuvo mejores resultados que los del otro grupo (animación -> narración). Por el contrario, si la narración y la animación fueron simultáneas, los estudiantes del grupo (animación + narración + texto), es decir, con material verbal redundante, obtuvieron peores resultados que el otro grupo (animación + narración). El primer resultado se explica por la teoría del procesamiento dual de la información, ya que al observar primero la animación quedaban los canales auditivo y visual libres para procesar la información. El material redundante, entonces, ayudó a establecer conexiones entre las palabras escritas y escuchadas. El segundo resultado muestra la sobrecarga que se produjo en el canal visual al competir por recursos cognitivos el procesamiento de la animación y el texto en pantalla.

Hay que considerar que el diseño del experimento contempla la utilización de una animación de corta duración. En las aplicaciones reales, sin embargo, es muy probable que no sea factible - ni deseable - utilizar el formato secuencial. Lo ideal entonces, bajo el modo de presentación simultáneo es limitarse a la animación con narración, sin redundancia alguna.

Así se establece el principio de redundancia, el cual indica que "los estudiantes aprenden mejor de una animación y narración que de una animación, narración y texto si la información visual es presentada simultáneamente a la información verbal" (Mayer y Moreno, 2000).

Se debe aclarar aquí que el principio de redundancia es uno de los que necesita mayor experimentación, ya que se han obtenido resultados aparentemente contradictorios. De hecho, Sweller (2005 b), aunque indica que "las personas aprenden mejor cuando la misma información no se presenta en más de un formato" no tiene la misma definición de redundancia que Mayer.

\section{Principio de señalización}

La sobrecarga que interfiere con el aprendizaje, se puede disminuir de varias maneras. Mayer (2005) dedica el capítulo doce en su totalidad a analizar varias formas de reducción de lo que él considera carga no esencial. Para él, los principios de coherencia y redundancia descritos anteriormente, son esenciales en dicha reducción. Además incluye los principios de señalización, contigüidad temporal y espacial entre las herramientas para disminuir la 
sobrecarga. En este trabajo nos referiremos solo al principio de señalización, ya que es utilizado frecuentemente en el material multimedia que elaboramos. De manera concisa este principio establece que en una presentación multimedia se aprende con mayor profundidad cuando se añaden claves que ayudan a resaltar la organización de la información esencial. Esto tiene sentido a la luz de la arquitectura cognitiva, ya que facilita la selección de palabras e imágenes, así como los procesos de integración y creación de esquemas. Cabe notar que la señalización puede darse en la modalidad auditiva (por ejemplo con cambios en el tono de voz) o bien en la modalidad visual, añadiendo elementos tales como flechas o cajas de color. En Mayer y Moreno (2000) se define el principio de señalización indicando que "el estudiante aprende mejor cuando se integra en la explicación algún tipo de señal que sirva de guía en la organización de la información"

\section{Implementación de los principios en el material elaborado}

Como se mencionó anteriormente, en el curso de cálculo que impartimos hubo necesidad de elaborar material que sirviera de complemento a las lecciones presenciales y que permitiera al estudiante repasar ciertos temas por su cuenta. En la producción del material multimedia, integramos nuestra experiencia como docentes, un poco de intuición y por supuesto los conocimientos resumidos en los principios de la teoría cognitiva del aprendizaje multimedia. Cada uno de los ejercicios que elaboramos integra audio en la forma de narración e imágenes, cumpliendo así con el principio de multimedia.

Absolutamente todos los ejercicios utilizan la modalidad auditiva y la visual, respetando también el principio de modalidad. Por otra parte, de acuerdo con el principio de coherencia, se eliminó cualquier sonido o imagen ajenos a lo expuesto. 




Figura 7: utilización del principio de señalización

El material consiste en una serie de ejemplos resueltos donde se va narrando paso a paso la solución de un problema propuesto. Para lograr que el estudiantado centre su atención en un detalle particular del desarrollo, se utilizaron diversos recursos de señalización, que dependen del software empleado. En general, los programas de autoría multimedia permiten añadir flechas, cajas de texto o de color como se aprecia en las Figuras 7 y 8 , tomadas del material elaborado.

En la Figura 8 podemos observar una caja rectangular con cierto nivel de transparencia ubicada sobre la ecuación $y=e^{-1}$. Aunque la caja carece de texto, la idea es centrar la atención en la ecuación en el momento preciso en que la narración hace mención a ella. 


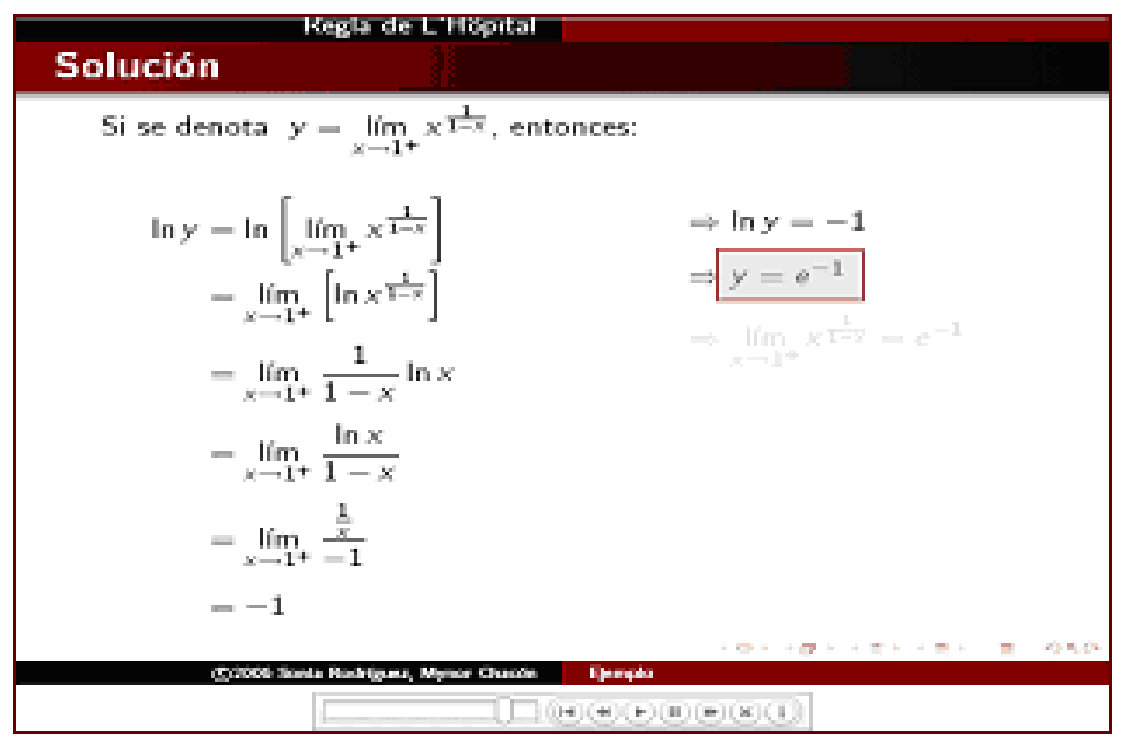

Figura 8: otro tipo de señalización utilizado

\section{Opinión de los estudiantes con respecto al material elaborado}

Para obtener la opinión de los estudiantes, se realizó una prueba piloto durante el segundo ciclo del 2005. A un grupo de aproximadamente 30 estudiantes se les presentó parte del material multimedia. Tuvieron la opción de observar el material fuera de clase en cualquier computadora con acceso a Internet y se les pidió responder a las siguientes preguntas: ¿les parecen claras las explicaciones?, ¿consideran útil el material?, ¿tienen alguna sugerencia que permita mejorar dicho material?

Con respecto a la primera pregunta el cien por ciento del estudiantado consideró que las explicaciones eran bastante claras, fáciles de comprender y muy dinámicas. La mayoría de la población estudiantil - salvo una excepción - mencionó que la narración se escucha bien. Algunos opinaron que la narración transcurre de una manera rápida, pero creen que esto no presenta mayor problema pues el material tiene la opción de pausar y devolverse.

La respuesta para la segunda pregunta resulta bastante consistente, todos consideraron que el material es muy útil, aunque lo enfocaron desde distintas perspectivas. Por ejemplo, algunos opinaron que es útil principalmente para la población estudiantil que repite el curso, otros respondieron que resulta de gran utilidad para repasar, mientras que para un tercer grupo el material es un buen complemento a los ejercicios vistos en clase y propuestos en el cuaderno de trabajo. 


\section{Re: Ejercicios Inducción.}

\section{de Sunday, 16 de October de 2005, 09:44}

Bueno, realmente le encontre bastante utilidad a la práctica mas que todo porque la explicación es sólida y concisa, además de que no presenta ningun problema significativo de audio y la sincronización con la explicación en pantalla (visual) es bastante buena. Por cierto, también carga bien rápido.

Realmente el enfoque esta bien fundamentado y abarca con la práctica la correcta aplicación de ejercicios de inducción al menos para nuestro curso.

Como sugerencias o mejoras, no hay mucho que apuntar, quiza la especificación más detallada de algunos pasos en los ejercicios $u$ otros detalles que se omiten durante la explicación.

En general, ha sido una gran idea!!!

Mostrar mensaje anterior | Partir | Borrar | Responder

Figura 9: opinión de un estudiante sobre el material, expresada en un foro

Entre las sugerencias hechas por los estudiantes, las que consideramos más útiles para mejorar el material son las siguientes:

- Añadir explicaciones suplementarias en algunos puntos particularmente difíciles de la explicación.

- Utilizar voces de distintos narradores en los ejercicios, con el fin de no caer en la monotonía auditiva.

- Realizar ejercicios de mayor dificultad, y agregar alguna especie de quiz que permita al estudiante verificar su aprendizaje.

- Poner más ejercicios en línea.

\section{Re: Series}

de - Saturday, 22 de October de 2005, 22:40

Esta vez note algo que en el caso de los ejercicios de inducción, no vi, los detalles. Me parece que los detalles son una buena maneras de despejar dudas o realizar explicaciones o demostraciones que pueden volver el ejercicio muy tedioso de escuchar para el estudiante, y de explicar para ustedes

No me desagrada la mnera de explicar o la voz del profesor, pero es positivo que varíen con otras voces y formas de explica, para que el estudiante pueda aprenderr de manera más dinámica

Ojalá y puedan poner más ejercicios en línea, para el próximo examen.

Estos pueden quedarse así para ciclos futuros, no necesitan corrección

Mostrar mensaje anterior | Partir | Borrar | Responder

Figura 10: opinión de un estudiante con sugerencias 
Concluimos mencionado que durante el año 2006 se continuó con la elaboración y revisión del material y durante el presente año se está trabajado en dos direcciones: se pondrá el material en Internet, a disposición de todos los estudiantes de la cátedra y se considera una nueva evaluación que involucre todo el material elaborado hasta el momento y que incorpore las sugerencias hechas por los estudiantes después de la prueba piloto.

\section{Conclusiones y trabajo futuro}

Debido al auge logrado en los últimos años por las aplicaciones multimedia como herramientas en los procesos de enseñanza-aprendizaje, se hace imperioso su análisis bajo un riguroso marco teórico que proporcione una base científica y a su vez aclare bajo qué condiciones contribuyen al aprendizaje. La Teoría de carga cognitiva y la Teoría cognitiva del aprendizaje multimedia proporcionan bastante claridad sobre el proceso del aprendizaje con tecnología, aunque existen otros enfoques. Los principios prácticos que se han derivado de las investigaciones en este campo constituyen una buena base para la elaboración de este tipo de material.

Ante las aplicaciones multimedia es común encontrar reacciones extremas: por un lado los que consideran que este tipo de material por sí solo resuelve los problemas de la educación y por otra parte los que basándose en anteriores espectativas no cumplidas por los nuevos medios (por ejemplo, la televisión nunca logró el impacto en la educación que se esperaba al inicio), predicen que cualquier otro intento está destinado al fracaso. Los autores consideran que una posición realista, basada en las teorías mencionadas, permite utilizar con éxito herramientas complementarias a la enseñanza tradicional.

El material multimedia, como se implementó en el curso de cálculo, es innovador, sobre todo en lo que respecta al área de la enseñanza de la matemática. Utiliza un discurso similar al de una clase presencial, con la diferencia que ahora la población estudiantil tiene acceso al material vía internet a cualquier hora del día y no solo en la hora de clase.

El proceso de elaboración y evaluación del material multimedia va a continuar, explorando nuevas opciones tales como la grabación de lecciones completas. 


\section{Referencias}

Arteaga, Gabriel y Pimienta, Hernán. (2006). Memoria operativa y circuitos corticales. Revista de la Facultad de Medicina de la Universidad Nacional de Colombia 54. 248-268.

Baddeley, Alan D. (2002). Is Working Memory Still Working? European Psychologist 7 (2), 85-97.

Clark, Richard E. (2005). Five Common but Questionable Principles of Multimedia Learning. En The Cambridge Handbook of Multimedia Learning. Cambridge, Estados Unidos: Cambridge University Press.

Etchepareborda, Máximo C. y Abad-Mas, Luis. (2005). Memoria de trabajo en los procesos básicos del aprendizaje. Revista de Neurología 40 (Suplemento 1), S79-S83.

Kristiansson, Karin. (1981). Multimedia Instruction: High Learning, Low Cost. Journal of Extension. 9-13.

Mayer, Richard E. (editor) (2005). The Cambridge Handbook of Multimedia Learning. Cambridge, Estados Unidos: Cambridge University Press.

Mayer, Richard E. y Moreno, Roxana. (1998). A Cognitive Theory of Multimedia Learning: Implications for Design Principles. Ponencia presentada en Reunión Anual de ACM SIGCHI Conference on Human Factors in Computing Systems, Los Angeles, CA. Recuperado el 20 de enero de 2006, de http://www.unm.edu/ moreno/

Miller George A. (1956). The Magical Number Seven, Plus or Minus Two: Some Limits on Our Capacity for Processing Information. The Psychological Review 63, 81-97. Reproducido con permiso del autor en el sitio: http://www.musanim.com/miller1956/

Molholm, Sophie et al (2006). Audio-Visual Multisensory Integration in Superior Parietal Lobule Revealed by Human Intracranial Recordings. Journal of Neurophysiology 96, 721-729.

Moreno, Roxana y Mayer, Richard E. (2001). Getting the Message Across: The Role of Verbal Redundancy in Multimedia Explanations. Ponencia presentada en la Conferencia AERA 2001, Seattle, WA.

Moreno, Roxana y Mayer, Richard E. (2000). A Learner-Centered Approach to Multimedia Explanations: Deriving Instructional Design Principles from Cognitive Theory.

Interactive Multimedia Electronic Journal of Computer-Enhanced Learning 2, (2). Recuperado de http://imej.wfu.edu/articles/2000/2/05/index.asp

Moreno, Roxana y Mayer, Richard E. (1999). Visual Presentations in Multimedia Learning: Conditions That Overload Visual Working Memory. Ponencia presentada en: Third International Conference on Visual Information Systems, Amsterdam, The Netherlands. 
Mousavi, Seyed Y., Low, Renae y Sweller, John. (1995). Reducing cognitive load by mixing auditory and visual presentation modes. Journal of Educational Psychology 87, 319334.

National Research Council (2000). How People Learn: Brain, Mind, Experience, and School: Expanded Edition. National Academy Press.

Paivio, Allan. (2006). Dual Coding Theory and Education. Ponencia presentada en: Pathways to Literacy Achievement for High Poverty Children, University of Michigan. Recuperado de: http://www.umich.edu/ rdytolrn/pathwaysconference/pathways.html

Paas, Fred G., Renkl, Alexander y Sweller, John. (2004). Cognitive Load Theory: Instructional Implications of the Interaction between Information Structures and Cognitive Architecture. Instructional Science 32, 1-8.

Sweller, John. (2005 a). Implications of Cognitive Load Theory for Multimedia Learning (Chapter 2). En The Cambridge Handbook of Multimedia Learning. Cambridge, Estados Unidos: Cambridge University Press.

Sweller, John. (2005 b). The Redundancy Principle in Multimedia Learning (Chapter 10). En The Cambridge Handbook of Multimedia Learning. Cambridge, Estados Unidos: Cambridge University Press.

Sweller, John, van Merriënboer, Jeroen y Paas, Fred. (1998). Cognitive Architecture and Instructional Design. Educational Psychology Review, 10 (3), 251-296. 